\title{
DISEÑANDO UNA RECEPCIÓN PARTICIPATIVA PARA UNIVERSOS TRANSMEDIA: ROLES Y DESAFÍOS
}

Javier HERNÁNDEZ RUIZ

Universidad San Jorge Zaragoza

hernandez@usj.es

$\mathbf{I}$

ntroducción y metodología

Este artículo $^{1}$ nace de mi experiencia híbrida como investigador en las narrativas transmediáticas y como creador transmedia, principalmente del universo de «ficción total»Plot 28 (www.plot28.

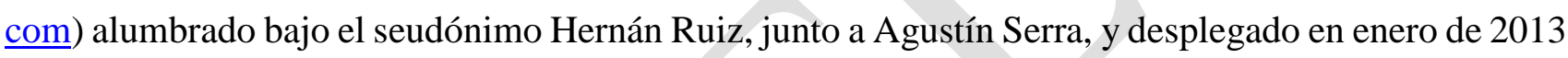
tanto en la web como a través de un app para iPad. Del cruce de esa experiencia creativa y de la reflexión teórica nace esta propuesta que puede servir tanto para académicos como para diseñadores de producción y creadores transmediales. La metodología aplicada es hija, por tanto, de este cruce entre aportaciones teóricas sobre el tema, con referencias al marketing, a los estudios de recepción, a los estudios culturales, así como a los Comparative Media y New Media Studies, con las conclusiones recabadas de mi propia singladura como diseñador de un universo transmediado. Sin duda, el transmedia - lo utilizo conscientemente como sustantivo - requiere nuevos retos metodológicos, que han sido resumidos con lucidez por Sánchez-Mesa y Baetens (2017). Teniendo en cuenta todo ello, mi objetivo es que estas aportaciones puedan servir a los que quieran emprender una aventura creativa de diseñadores de producción - este es el rol principal desde el que escribo según lo establecido por Costa Sánchez (2013: 564) ${ }^{2}$ - en el creciente panorama del transmedia storytelling, término de gran complejidad sobre el que he aportado en otra publicación mi propia perspectiva (Hernández, 2017). Me aproximé a algunos aspectos relacionados con este tema en el epígrafe «Difusión en la placenta de la cultura digital participativa» del artículo de Espéculo (Hernández, 2015), pero aquí me dispongo a abordarlos específicamente.

\footnotetext{
1 Este artículo se enmarca dentro del proyecto Narrativas transmediales: nuevos modos de ficción audiovisual, comunicación periodística y performance en la era digital (Referencia CSO2013-47288-P), dirigido por el profesor Domingo Sánchez-Mesa Martínez. Ministerio de Economía y Competitividad

${ }^{2}$ Hablaríamos de diseñadores de un proyecto transmedia para referirnos al equipo que se ocupa del trabajo de planificación, por cuanto a: Mundo de la historia, trama principal y secundarias, personajes principales y secundarios, plataformas / contenidos, audiencias, modelo/s de negocio.
} 


\section{Destinatarios del transmedia storyteller}

No sabemos hasta qué punto una propuesta de narrativa transmedia tiene un target específico y distinguible. Para aproximarnos a ello debemos tener presente las características de los destinatarios de otras estrategias y dispositivos comunicativos vinculados a los new media, así como a otros productos derivados de las TICs. Las narrativas participativas desarrolladas en el marco de la cultura digital también pueden arrojar luz sobre esta cuestión, sabiendo que están determinadas por el impacto del público conectado a través de las redes sociales. La mercadotecnia contemporánea establece que el destinatario es un personaje-cliente porque, en realidad, son como personajes ideales a partir de estudios reales que perfilan cómo sería. Es como si un creador de ficción literaria o cinematográfica, a la hora de construir sus mundos ficcionales (storyworlds), tuviera muy presentes a sus próximos interlocutores en un proceso dialógico. Algo parecido acaece en el diseño de producción transmedia: siempre con la vista puesta en esos destinatarios finales, calibrando sus necesidades, así como la posibilidad de comprender los mensajes puestos en circulación. Igualmente, en estos procesos creativos se impone una escalabilidad que ya señalan determinadas teorías mercadotécnicas: los destinatarios activos en primer lugar, luego los inactivos, los potenciales, los probables y, finalmente, el resto del mundo.

Las fluctuaciones y cambios en los mercados son realidades indiscutidas hoy día. En los últimos tiempos esa metamorfosis acelerada se ha focalizado en los consumidores, principalmente como consecuencia de la penetración de Internet y de las TICs, fenómeno acompañado de la progresiva implantación de una sociedad participativa gracias a las redes sociales. Al menos en su diseño ideal, el nuevo consumidor digital presenta estas señas de identidad propias de los millenials:

- Es un usuario que domina con cierta soltura las tecnologías digitales.

- Posee habilidades desarrolladas en comunicación interactiva.

- Es breve y rápido en la lectura de textos de cualquier índole.

- Es capaz de consumir, difundir y crear contenidos en diferentes medios.

- Puede desarrollar diferentes actividades a un mismo tiempo.

- Es experto en comprar sin necesidad de ir a puntos de venta físicos.

- Antes de aprender a hablar y a escribir, aprendió a manejar un ordenador e hizo de la máquina una extensión de sus sentidos y de la forma de mantener contacto con el mundo que le rodea.

- Vive ajeno a conceptos como territorios, fronteras, horarios, frecuencias radiales, programación televisiva.

- Su día a día está cercano a la inmediatez, la ausencia de tiempo, la personalización mediática, el acceso a fuentes de bases de datos en cualquier momento a su antojo.

- Nació en la era digital. El nuevo consumidor transmedia lo es de manera natural, sin ser plenamente consciente de su realidad transmedial, ya que es su estado normal, la norma. 
En consecuencia, no es extraño que McCracken (2005) proponga que tengamos que actualizar el término consumidores por el de "multiplicadores", que implica su compromiso consciente con un producto o marca.

La revolución digital, que llegó a la producción de contenidos audiovisuales la última década del siglo XX permitió una flexibilización en la gestión de contenidos. Internet y la televisión digital han contribuido a una gran metamorfosis de modelos de negocio que está revolucionando el sector audiovisual. La interrelación con la informática y las telecomunicaciones lleva a la convergencia industrial; de ahí a la convergencia cultural de la que habla Jenkins hay solo un paso, todo ello en el marco de un ecosistema mediático en el que, como el citado autor expresa a propósito de cualquier contenido digital: «If it doesn't spread, it's dead» (Jenkins et alii, 2013). Dichas mutaciones han afectado al destinatario modélico de los productos digitales. ¿Qué conceptos tenemos que tener en cuenta para pasar del pasivo al activo? El concepto ATAWADAC (AnyTime, AnyWhere, AnyDevice, Any Content), según el cual el consumidor digital accede, difunde o crea cualquier contenido en cualquier momento, desde cualquier lugar y sobre cualquier dispositivo. Por lo que cabe preguntarse: ¿qué tipo de contenidos consume y cuáles son sus favoritos?, ¿en qué momento, en qué lugar, de qué modo y sobre qué dispositivos accede a ellos? Pistas de ello aportó en 2012 la consultora norteamericana Latitude Research, que realizó una encuesta internacional para conocer la tendencia de los contenidos que aparecen en la red, supuestamente muy versátiles y casi siempre vinculados a las historias que allí se muestran. Las conclusiones fueron conocidas como The 4 I's of Storytelling: Out of the Screen, into My World; a saber: inmersión (Inmersion), interactividad (Interactivity), integración (Integration) e impacto (Impact).

\section{Hacia un público objetivo para el transmedia storyteller}

Previamente a cualquier intento de acotamiento de este tipo de audiencia, se impone analizar el ecosistema real del consumidor desde el acceso a la tecnología — conexión a Internet, velocidad, dispositivos a su alcance para conectarse a Internet, crear contenidos y calidad de los mismos-, nivel socioeconómico —estatus, poder adquisitivo, contactos, influencia, tipo de población a la que pertenece, profesión, edad y sexo, redes sociales que utilizan-, nivel cultural —formación, conocimientos, educación, religión, tradición, costumbres y modas-, compromiso social y solidario, etcétera. Este análisis corresponde a los estándares que determinan el target para cualquier campaña de marketing contemporánea, teniendo muy presente que el consumidor transmedia es «glocal» — global y local— y, por tanto, pudiera tener más amigos en el mundo que en su lugar de residencia, si bien este emplazamiento determinará sus posibilidades y hábitos de acceso, difusión y creación de contenidos dentro y fuera de la red; al mismo tiempo, su nivel sociocultural y el estatus sociopolítico de la población en la que queda encuadrado influirán en el modo de acceder, consumir, difundir o crear un tipo determinado de contenidos. La audiencia transmedia suele pertenecer a una o varias tribus globales asociadas a redes sociales y ostenta un estatus social dentro de estas que depende de su nivel 
de activismo e involucración — compromiso - y, a la vez, de su capacidad de generar empatía, sorpresa, juego o deseo. Tiende a ser ese tipo de usuario que se involucra directa o indirectamente en la fabricación de mensajes y contenidos, lo que Bruns (2007) denominó produsage y que apunta a los prosumidores de los que hablaremos más adelante.

Una de las características de la tecnología de consumo surgida en los últimos años es que abre nuevas perspectivas creando la necesidad de estar conectado a la información a través de diferentes plataformas que sirven a la actividad laboral y profesional, pero también al ocio; y es aquí donde se disputa la parte del león del beneficio económico de esta nueva realidad... Como resultado de la presión combinada del mercado y del estatus social, a menudo el individuo se ve pendiente a la vez de una lógica multidispositivo - televisión, teléfono móvil, ordenador o nuevos aparatos que combinan características de los anteriores-. Estamos ya inmersos, pues, en la multitarea digital y este es un terreno abonado para las estrategias transmedia. Una narrativa de este tipo apela hacia una inmersión que amplificará las emociones personales: el espectador-consumidor adiestrado en el escenario mediático actual ya no se conforma con una única experiencia perceptiva sino que desea sentirse parte del relato, aspirando a ser partícipe de forma activa y comunitaria en las producciones culturales que consume, más allá de los límites que anteriormente venían impuestos en los modelos verticales (Abellán y De Miguel, 2016: 2).

Teniendo en cuenta que el usuario ha ido mutando desde un consumo de medios y canales a otro de contenidos, al final aquél acaba autoprogramándose a través de las distintas plataformas. Esto ocurre ya en las llamadas «narrativas inmersivas» (pervasive narratives), entre las que se encuentran las transmediáticas. Así pues, todas estas realidades mutantes deber ser tenidas muy en consideración desde el diseño de producción transmedial a la hora de prefigurar ese público objetivo.

\section{Perfilando los usuarios y sus motivaciones}

Para definir el perfil del usuario del transmedia storytelling se han de tener en consideración las lecciones de una mercadotecnia clásica, que indica que los perfiles tradicionales de los consumidores están catalogados según unas categorías, y hay que considerar que hay una manera de comunicarse con cada uno de ellos, también dependiendo de los contenidos que se van a distribuir a dichos destinatarios. Esos consumidores, para nosotros mejor usuarios, tienen determinados móviles de elección a la hora de consumir un producto, servicio o contenido, de ahí que se hable de moda, orgullo, interés, afecto, comodidad, seguridad... A esos móviles cabría añadir un cuarteto de motivaciones que se ajustarían mejor a la lógica transmediática:

1. Ser/estar: impulso que conduce a formar parte de una comunidad generada a partir de la audiencia.

2. Coleccionar: tendencia a tener todas las piezas que conforman un producto transmedial, a disponer de una visión completa del mismo.

3. Participar: deseo de interactuar, de ser parte de, de estar dentro del juego. 
4. Protagonizar: impulso a convertirse en un líder de opinión y a la creación dentro de esa comunidad / audiencia.

Ardévol et alii (2010) definen las prácticas mediáticas según las personas responden a objetivos simultáneos -intercambio de información, placer estético, juego, participación política- que generalmente se encuentran relacionados con la producción y el consumo de narrativas. Para un mismo producto los móviles de elección pueden variar según cada individuo e incluso en el mismo individuo, en función de momentos y circunstancias. Ese sujeto, por lo general, obedece a varios móviles de elección al mismo tiempo, con predominio de uno o más de ellos. Estas son consideraciones previas que para un diseñador de producción transmedia opera como mapeo de una realidad - los usuariosque de continuo hay que contrastar. Cuanto más detallado sea el mapa que de esa realidad dispongamos, mayores garantías a la hora de hacer navegar con éxito nuestro producto en el complejo mercado contemporáneo.

\section{Definiendo los intereses de los potenciales usuarios}

Hasta tal extremo el ecosistema digital transmedia ${ }^{3}$ está en constante transformación que el diseñador de producción tiene que estar adiestrado para hacerse las preguntas oportunas en cada momento y situación; solo entonces se activará una cultura tan dinámica como el entorno al que trata de dar respuesta. Y ¿cuáles son los interrogantes adecuados que el diseñador de producción transmedial lanzará para conocer un target en este campo específico? Se planteará, por ejemplo, qué blogs, magazines, periódicos y libros leen, qué autores les gustan, las películas, programas de radio y televisión que ven, directores de cine que les gustan. Se interrogará también sobre las condiciones de consumo cultural: cuándo, dónde y cómo visionan, en qué dispositivos y momentos oyen música; ¿cómo se informan?, ¿qué tipo de plataformas utilizan?, ¿cuándo y cuánto podrían participar activamente?, ¿cuán participativos son?, ¿cuántas horas pasan en cada plataforma?, ¿qué plataformas prefieren para consumir determinados contenidos? Cuando se dan, los estándares de producción profesionales en el campo transmediático estos sondeos de mercado están contemplados en un capítulo de preproducción. Pero muchas veces la intuición o el voluntarismo sustituyen a esos procedimientos reglados y profesionalizados lastrando los diseños e incrementando los riesgos.

Bien sea de una manera profesionalizada o intuitiva, una vez respondidas estas cuestiones, se podrá delimitar qué territorios y valores se comparten con los destinatarios, dónde y cómo encontrarse con ellos, cómo hablarles y cómo invitarles a jugar a través de los adecuados anzuelos. El consumidor es infiel por naturaleza y, cada día más, busca estímulos nuevos en mayor o menor medida; el mercado busca estos estímulos y los talentos que los crean fuera de sí, para luego canibalizarlos y hacerlos propios. En el nuevo escenario de la cultura digital participativa estos estímulos y sus creadores van acompañados de sus propias audiencias y «comunidades de consumo» (Kozinets, 1999), esto es lo que

\footnotetext{
${ }^{3}$ Cada vez más se va abriendo paso una perspectiva de ecosistema mediático en los estudios del sector, como pone de manifiesto José Van Diijck en su obra The Culture of Connectivity: A Critical History of Social Media .
} 
explica que algunos videobloggers ganen más que algunos altos directivos. En marketing la aspiración máxima de una marca o producto es que el consumidor los sienta como propios y el ecosistema digital transmedia está lleno de autopistas que favorecen este fenómeno de propaganda inducida, casi siempre de un modo viral y global. Así se explica que en el marco de la cultura digital participativa las marcas busquen aliados — líderes de opinión — en las redes sociales y demás plataformas colaborativas, como base de su estrategia de captación, seducción y fidelización de fans para desarrollar sus estrategias de relaciones públicas $360^{\circ}$ con eventos en el territorio offline y activismo online, lideradas por evangelistas de la marca, a cambio de prestigio, producto o dinero. En la lógica transmedial, hija igualmente de esa cultura, estos protocolos deben estar ya interiorizados.

\section{Del consumidor al prosumidor}

Consumidor es un término que está demasiado apegado al consumo de productos tangibles, por eso en las estrategias transmediáticas se suele preferir el vocablo usuario. Sin embargo, en el contexto de la cultura participativa ${ }^{4}$, el prosumidor, concepto lanzado por Toffler en 1980 en su célebre libro La tercera ola, ha arraigado en este ámbito transmedia desbordando al tradicional consumidor; ese tránsito está inmerso en el ciclo mismo de vida de los productos transmediales y su relación con los usuarios y sus motivaciones, tipologías y personalidades. Una de las principales consecuencias de esa revolución digital es el acceso universal y creciente a la Red desde cualquier dispositivo, propiciando de hecho una democratización sin precedentes del consumo de contenidos; en este contexto los creadores de esos contenidos online ponen al servicio de los consumidores diferentes herramientas para la participación e interacción en diferentes grados de modo gratuito, más las que el prosumer encuentra o genera por sus propios medios. Así pues, las barreras que podría construir el poder adquisitivo quedan reducidas por el talento, la habilidad tecnológica y social, el carisma y la creatividad de ese nuevo consumidor-productor.

El diseñador de producción de contenidos transmedia debe facilitar esas herramientas en el marco de una narración inacabada y gamificada, con el fin de que los usuarios sean sus aliados en la creación de una comunidad / audiencia capaz de generar contenidos. Si no hay audiencia preestablecida, el diseñador de producción transmedia tendrá que eliminar barreras de entrada como el precio o la complejidad de su universo, al tiempo que ha de crear su producto por etapas - escalabilidad - siempre con complicidad de la audiencia. La clave para una estrategia de contenido de éxito es asumir la escalabilidad de los procesos. Diferentes estudios de mercadotecnia han venido estableciendo que se despliegan tres fases de compromiso de la audiencia: 1/ descubrimiento, 2/ experiencia, 3/ exploración. Así pues, es vital determinar cuál es el contenido que se requiere para cada fase y cuáles son los objetivos para cada una de ellas. No reconocer que existen estas etapas de engagement puede conducirnos a proponer a la audiencia hacer mucho trabajo antes de tiempo - que la mayoría no hará- y, en consecuencia, su relación con el contenido no superará la etapa

\footnotetext{
${ }^{4}$ Concepto desarrollado por Henry Jenkins en 1992 cuando hablaba de los textual poachers.
} 
de descubrimiento. Una vez que se han establecido los diferentes segmentos de nuestros destinatarios, asociados a distintos niveles de compromiso, se debe poner en juego una dinámica de participación y cocreación entre la comunidad. Hayes (2007) retrata este proceso in crescendo: primero los consumidores con mayor grado de compromiso lideraran el itinerario convirtiéndose de consumidores a distribuidores — la «propagabilidad» de la que hablan Jenkins, Ito y Boid (2016)—, luego entrarán en juego los críticos, posteriormente los editores y finalmente los creadores —máximo nivel de prosumición-, arrastrando a otros usuarios de la comunidad en este viaje «evangelizador».

\section{Inmersos en una cultura participativa}

La cultura participativa, una de las consecuencias de la revolución digital ${ }^{5}$, viene siendo promovida por la conjunción de tres tendencias: nuevas herramientas y tecnologías para los consumidores, promoción del método DYA — do it yourself - para las producciones mediáticas y, finalmente, las tendencias económicas que favorecen la integración horizontal de un conglomerado de medios integrados con flujo de imágenes, ideas y narrativas a través de múltiples canales. Consecuencia inmediata de esa cultura participativa son los nuevos métodos de financiación — crowdfundingy de creación en masa - crowdsourcing-, así como los Contenidos Generados por los Usuarios (CGU). Todas ellas son herramientas colaborativas basadas en la inteligencia colectiva —-según Levy (2004) - y asociadas al concepto de open innovation, que no se entendería sin una progresiva democratización tecnológica.

Jenkins en su citadísimo libro Converge Culture (2006) alude al «empoderamiento de los usuarios amateurs» para producir contenidos en este nuevo contexto de la cultura digital participativa. E insiste en que esto conlleva cambios profundos en las figuras del productor y del consumidor, pero también en las relaciones que se establecen entre ellos, que deben asumir unas fronteras cada vez más difusas, como señala Deuze (2007). Otra consecuencia de ese terremoto tecnológico y social contemporáneo es el fandom - reino de los fans- Como en el caso del crowdfunding, este término también remite a esos dos actantes del proceso, productores y usuarios respectivamente. Pero esa revolución también afecta a los creadores, por lo que Jenkins se refiere a un autor colaborativo que supera la concepción individualista del autor romántico y que, a su vez, se abre a la participación de los usuarios para compartir ese universo creativo. En este contexto, agudamente radiografiado por Gaunlett (2011), en el que el usuario se ha convertido en el dueño de la web 2.0 seleccionando y promocionando contenidos pero también creándolos, resuena con pleno sentido el eco del temprano concepto de intercreatividad, término introducido por Tim Benners-Lee (1997).

\footnotetext{
${ }^{5}$ Este término fue puesto en circulación por Jenkins en la fecha temprana 1992 en un texto titulado Textual Poachers, aludiendo a la cultura fan. En 2016 el mismo Jenkins, junto a Ito y Boyd, ha planteado otro texto que amplía este concepto, titulado Participatory Culture in a Networked Era. A Conversation on Youth, Learning, Commerce, and Politics. Jenkins ha venido insistiendo que las culturas son participativas, lo han venido siendo en la Historia, mientras que la tecnología es interactiva.
} 
Volvamos a esa estrategia participativa que parece invadirlo todo hoy día. Buskqvist (2009) distingue entre participación, sostenida por las estructuras socioculturales, y la interactividad, en la que intervienen más activamente los mass media y la tecnología, distinción que asumirá, como hemos señalado, Henry Jenkins. Desde enfoques sociológicos se ha insistido en contextualizarla en el capitalismo digital, el trabajo inmaterial dominante y asociada a esa cultura participativa que desembocará en la prosumición. Buskqvist concibe la interactividad con un cuarteto definitorio: primero como un proceso comunicativo (por eso lo conecta con la respuesta inherente), en segundo lugar como un distintivo tecnológico, en tercero como una interacción social, entre creadores y consumidores y entre usuarios entre sí, y finalmente como un control consciente por parte del usuario.

Más allá de las discusiones teóricas, Carpentier (2011) opta por una catalogación más operativa y distingue varios tipos de interactividad:

1. De usuario a usuario.

2. Del usuario al «documento» (podemos entenderlo aquí como propuesta, producto).

3. Del usuario al sistema.

Y asegura que la interactividad puede ser un camino para intentar un proceso de producción más democrático. No están de acuerdo con tan optimista visión algunos pensadores neomarxistas como Andrejevic (2007), acusándola de ser un medio para monitorizar el marketing o para darle una falsa apariencia de democratización. No es este el caso de la mayoría de las propuestas transmedia de ficción homologadas, donde generalmente el usuario no es un sujeto alienado sino alguien libre que deviene interactor tras un contacto proactivo con el universo en el que ha hecho inmersión. El tiempo tiene la palabra en este nuevo debate donde resuenan los ecos de los apocalípticos e integrados.

\section{Prosumidores y Contenidos Generados por Usuarios (CGU)}

Los universos transmedia ya no se dirigen solo a los interactores, lo hacen también a esta nueva tipologia de usuario transmedia que contribuya a la expansión del universo. Involucrar a la audiencia en la creación de valor generando contenidos para usos comerciales se viene planteando desde estudios como el de Thrift (2006) al tiempo que se vienen estudiando las potencialidades de «consumer media scope», es decir el comportamiento y las preferencias de los consumidores en las distintas plataformas y canales (Cham-Olmsted, 2005)... Mas ahora los diseñadores de producción transmedia han de abordar unos desafíos específicos en nuestro campo.

Ya hemos adelantado que los prosumidores constituyen una valiosa tipología de usuarios que son capaces de crear sus propios canales, contenidos y programas, a través de un personaje o personajes reales o de ficción — los avatares - que le representarán como marca — con su historia y sus valoresa través de blogs, memes, vídeo viral, etc. Estos consumidores proactivos, de gran éxito social y viral, son por supuesto productores de nuevos contenidos que empiezan a ser catalogados (Lastra 2016) ${ }^{6}$,

\footnotetext{
${ }^{6}$ Esta autora distingue entre Productor de Contenido Original (PCO) y Productor de Contenido Subyacente (PCS), en este caso adaptaciones o versiones de contenidos preexistentes.
} 
pero además se erigen en canalizadores - la propagabilidad a la que antes hemos aludido-, ya que con sus contenidos generan viralidad en diferentes canales consiguiendo una audiencia muy rentable si su nivel de tráfico es considerable y eficiente; en tal caso, estos canalizadores / propagadores acaban siendo patrocinados por las marcas para conseguir impactos en su audiencia o incluso acaban siendo absorbidos por grandes distribuidores de contenidos. En un universo transmedial en particular el canalizador se convierte en un embajador destacado del mismo ante una audiencia que puede ser vista como una «comunidad de consumo» (Kozinets, 1999).

¿Cómo fomentar la prosumición en un universo transmedia? En primer lugar, aprender de los ejemplos y de los feed-back que haya aportado la audiencia en otros productos, como señalan Green y Jenkins (2009). Ahí está la herding strategy, utilizada en películas mainstream, lo mismo que la estrategia Word-of-mouth (boca a boca) válida para cualquier producto cultural. Pero ¿cuál es el camino recorrido por el consumidor hasta llegar a ser prosumidor? Para ello se impone fomentar en el primero las actitudes que se resumen en el concepto inglés de engagement, muy presente en la literatura sobre el tema (Neale, 2010) y que podríamos traducir como compromiso o implicación de un usuario respecto a un producto cultural determinado; y en el caso del transmedia le lleva a implicarse en la ampliación de contenidos y en la expansión del universo.

El prosumidor y el canalizador son dos retoños de ese nuevo marco que es la «audiencia creativa» (Deltell, 2014: 34-35), pero no están exentos de nuevas problemáticas. Así pues, los intereses de los prosumidores y del promotor de los contenidos no tienen que coincidir necesariamente, ¿y acaso convergen los de los fans con la audiencia mayoritaria? ${ }^{7}$. Desde el punto de vista del diseño de producción esas potenciales tensiones con la audiencia hay que tenerlas muy en consideración. Para sortear el peligro se recomienda establecer unas reglas de juego muy claras, que no lleven a decepcionar a los potenciales prosumidores a la hora de realizar contenidos. Ciertamente un prosumer, un canalizador o un fan decepcionados se convierten en algo muy peligroso para nuestra propuesta (Edwards, 2012). Estos problemas pueden venir ya desde la fase de financiación, por ejemplo a través de una campaña de crowdfunding si las normas no son nítidas, porque eso puede lastrar el desarrollo del producto, como en parte ocurrió con El Cosmonauta (2012) generando malestar en algunos contribuyentes que no vieron satisfechas las promesas que les habían hecho por sus aportaciones. En 2011 Jenkins había dejado claro que la esencia del transmedia no está en la extensión, sino en el ADN que aporta la creatividad del storytelling. Eso supone una opción por la intensidad y la calidad de los contenidos interrelacionados en ese «mundo de historias envolventes» (Ford, De Kosnik y Harrington, 2011). Pero en estos «contenidos líquidos», propios de la revolución digital, no es solo importante la calidad informacional o ficcional sino propiciar su difusión y consumo de la manera más efectiva y participativa.

\footnotetext{
7 «According to M. L. Ryan (in this same volume), most of the guide books on TS address the audience as 'fans'. Should we understand 'readers', 'spectators' or 'players' as fans all the time? Can we expect the critical or aesthetic interest of 'traditional' audiences to be found in fan communities?» (Sánchez-Mesa y Aarseth, 2016).
} 
Todo ello nos conduce al crowdsourcing, término creado por el periodista Jeff Howe en Wired Magazine en 2006 que alude a compartir la creación de un mundo diegético en el marco de esa inteligencia colectiva y cultura participativa que rige nuestro tiempo: «Fan works transform the source text and one another in an iterative process, in constant conversation, to the degree that we can no longer locate an "official" or primary source. The transtext as a concept lets us see this profoundly decentered perspective» (Stein, 2017: 84). El ejemplo más temprano de crowdsourcing fue la serie Battlestar Galactica, cuando su productor publicó en el site oficial informaciones sobre la construcción de las tramas y las dificultades de la realización, que fueron contestadas con interesantes aportaciones de los usuarios. El célebre director holandés asimilado por Hollywood Paul Verhoven se ha servido de este sistema para crear su largometraje Tricked (2012), presentado en el VII Festival de Cine de Roma. Otro ejemplo relevante que tiene a la web como referente para la construcción de historias en cooperación es Runes of Gallidon (2008), analizado por Gallego (2011). Esto nos lleva a una de las innovaciones de esta era de conexión participativa: el Contenido Generado por el Usuario (CGU), normalmente a través de herramientas y contenidos canalizados por una Red convertida en «metamedio».

Para proponer CGU el consumidor ha devenido prosumidor y normalmente ha entrado en la lógica casi masónica de la cultura fan, que en breve comentaremos con detalle. ¿Cómo son esos contenidos promovidos por los usuarios? Hasta hoy son las series de televisión las que nos aportan la mayor experiencia en este sentido, sirviéndonos como modelo para otros productos culturales como el transmedia. Carlos Scolari en Narrativas transmedia (2013) desgrana las «estrategias de expansión y comprensión narrativa» que se fueron acumulando por la intervención de los espectadores fans a partir de las emisiones de la serie Lost de 2004 a 2010. He aquí las más destacadas:

1. Sincronizaciones (synchros) reconstrucción de momentos clave de la historia con edición sincronizada de vídeos de los usuarios mediante estética multipantalla.

2. Recapitulaciones (recaps).

3. Parodias.

4. Finales alternativos.

5. Falsos avances (re-cut trailers): vídeos remezclados que anuncian una película inexistente o bien cambian el sentido de un film conocido previamente.

6. Falsos openings: comienzo de un episodio con toque vintage, normalmente vinculado a la década de 1960 o 1970.

7. Mashups: combinación de imágenes y bandas sonoras de varios largometrajes o series.

\footnotetext{
${ }^{8}$ «[...] engloba todos aquellos formatos de contenido, disponibles a través de redes sociales y plataformas online, creados y distribuidos por uno o varios individuos no profesionales. El resultado final puede ser tanto la invención de una nueva obra como la adaptación de propuestas anteriores, siempre de forma libre y voluntaria. Este tipo de producciones se caracterizan por su alto componente creativo, por lo general son de carácter transmedia y fruto de dinámicas colaborativas en la web» (Fernández Castrillo, 2014).
} 
8. Adaptaciones: se cuenta una escena de la serie televisiva con variaciones de estética o estilo.

Hay más tipologías de productos, como el amplio espectro de los «memes» o genomas de la transmisión cultural, pero lo que aquí nos interesa es ver de qué modo este modelo aplicado a una serie televisiva se puede adaptar al despliegue transmedial, si bien teniendo presentes las peculiaridades de este nuevo género, así como los rasgos distintivos de cada universo de ese tipo en particular. Estamos, por tanto, ante un patrón con vocación universal donde se comparte lo esencial, en la medida que todos estos productos están inmersos en esa cultura participativa y en esa lógica del fandom. Situarse en este «reino de los fans» y movilizar las energías necesarias para llevar a cabo estos productos es el reto que todos los productos van buscando. El resultado es un universo cada vez más enriquecido.

Los CGU se realizan por propia iniciativa, recurriendo los usuarios a editores preestablecidos, herramientas que les permiten editar y compartir contenidos. Sin embargo, algunos proyectos digitales de cierta envergadura también facilitan la edición de estos contenidos con editores propios y, por ende, la profusión de prosumidores, evangelistas y canalizadores. Cuando el equipo correspondiente de un proyecto transmedia diseña las estrategias y tácticas colaborativas o de difusión en comunidades y redes, ha de tener en cuenta el mayor o menor grado de libertad participativa que le va a otorgar a los usuarios y potenciales prosumidores, según su nivel de implicación y puertas de acceso a nuestro canal o canales de contenidos, productos y servicios. Por tanto, el diseño del editor, su complejidad y su interacción marcarán la dinámica y el grado de participación y proactividad de los usuarios en el territorio que compartimos. Si desde el proyecto no se tiene posibilidad de desarrollar editores y canales propios, siempre se puede fomentar el uso de los ya presentes en el mercado, principalmente los gratuitos, como base social de nuestra plataforma. De hecho, aun teniendo editores de desarrollo propio, si se quiere producir una realimentación de audiencias, han de crearse dinámicas e itinerarios que unan a nuestros editores con los estándares del mercado. Por eso un diseñador de producción transmedia tiene que estar muy informado de cuáles son los dispositivos que pueden servir a sus potenciales creadores de contenidos, cómo y para qué. Las propuestas más exitosas dentro de esta política de participación digital de los productos culturales no solo han facilitado instrumentos de edición o tecnología aplicada para los usuarios, sino también un lugar donde albergarlos ligado a su universo de contenidos. El caso más celebrado es el de Starwars.com, espacio para depositar los fanfics con la condición de que se cedan los derechos a Lucas Films para engrosar el universo de contenidos galáctico. Este tipo de medidas explican la potencia, el desarrollo y la actividad del fandom de Stars War, posiblemente el más importante de la historia.

Otra de las maneras de fomentar los CGU son las estrategias de gamificación. No hay duda de que la estrategia lúdica ${ }^{9}$ funciona bastante bien a la hora de incentivar los procesos participativos, también en uno asociado al transmedia storytelling. Aquellos principios, categorías y dinámicas de juego son trasladables ahora a este nuevo desafío transmediático: aleccionar a los usuarios con retos,

\footnotetext{
${ }^{9}$ El transmedia storytelling es heredero de la dimensión lúdica de las cibernarrativas y del videojuego, cuya dimensión ergódica ha sido ampliamente estudiada por Aaarseth, quien viene proponiendo desde 2001 los Games Studies.
} 
juegos, quizs, gincanas virtuales, premios, metas, señuelos, etcétera. En la medida que tengamos una audiencia entretenida, incentivada, azuzada por estos procesos ergódicos, conseguiremos activarla para que puedan convertirse en canalizadores, evangelizadores, fans y prosumidores. Y de la misma manera que desde la instancia productora vamos a ofrecer editores, también desde esta misma instancia se puede recurrir a plataformas disponibles en el mercado — algunas de ellas gratuitas - que permitan monitorizar de forma continuada los procesos de ludificación y sus consecuencias, así como para conocer a nuestros usuarios activados en estos procesos; al mismo tiempo estas plataformas gamificadoras pueden proporcionar a nuestros potenciales fans y prosumidores instrumentos para que los utilicen en la generación de contenidos. Entre ellas podemos citar Badgeville, Brigdoor, Openbadges, Classrojo, Karmacrazy, etc.

\section{Creando comunidad a través de narrativas participativas}

Henry Jenkins insiste en sus libros que una de las señas de identidad del transmedia storytelling es su dimensión participativa, que afecta a todas sus facetas. Este rasgo es ponderado por algunos actores como uno de los más representativos de la cultura digital participativa que vivimos y se manifiesta cada vez más en determinadas propuestas. De hecho, como detallaremos más adelante, una buena parte de obras transmedia están marcadas por esa participación y por un sentido solidario. Tapscott y Williams (2006) proponen que para innovar en el despegue de comunidades, los procesos creativos de la industria y en los principios de participación se requieren cuatro ideas básicas: propensión a la apertura, intercambio entre pares, capacidad de compartir y actuación global. Por su parte Wenger et alii (2005) establecen que las comunidades se constituyen por tres intereses principales vinculados a lo tecnológico: interacción, publicación y atención. Estamos en una esfera creciente y de gran futuro, marcada por la intercreatividad - con fenómenos como el crowdsourcing $^{10}$ — que hace posibles social media products. Uno de los pioneros fue la social media movie Life of the Day (Kevin McDonald, 2011), producida por Ridley Scott y estrenada en el marco del Festival de Sundance 2011. Este audiovisual colectivo está integrado por ochenta mil videoclips —social media clips - subidos a Youtube por usuarios implicados de ciento noventa y dos países. En esta misma línea de narrativas participativas que retratan la cotidianidad con el concurso de prosumidores se planteó Britain in a Day, también producido por el director de Blade Runner para los Juegos Olímpicos de Londres 2012. Esta misma lógica de narrativas participativas también se ha extendido al ámbito de la publicidad y de lo que podríamos denominar transmedia branding. En este sentido destaca la campaña Montblanc 2011, liderada por el consagrado director germano Win Wenders con el expresivo título de The Beauty of a Second y que puso en marcha una exitosa plataforma de CGU. El éxito de la campaña hizo que se repitiera en 2012 con un título muy revelador The Montblanc Worldsecond, que aludía a esa dimensión de universo que generan estas propuestas que apelan a la inteligencia colectiva en red.

\footnotetext{
${ }^{10}$ Es un concepto alumbrado en 2006 por el periodista Jeff Howe en un artículo de Wired Magazine. Alude a cualquier proyecto ideado por especialistas que es compartido en la web para que otros usuarios se sirvan de él y lo mejoren.
} 
Las narrativas participativas han encontrado un canal adecuado en los ARG o juegos de realidad aumentada. El macroproyecto Whysoserious.com recoge acciones de las vidas reales de los usuarios, además de otros muchos elementos que lo conforman como un cajón de sastre colectivo y digital en torno al universo fan de Batman; se plantea desde una web pero en realidad, teniendo presente que se configura con retos, desafíos y aportaciones de la audiencia para configurar su particular mundo, puede contemplarse como un peculiar ARG. También lo es Conspiracy for Good (2010), ideado por Tim Kring, el creador de la serie televisiva Heroes, y financiado por Nokia. Es un singular proyecto con fines filantrópicos que pretende promover un cambio positivo en el mundo a través de la participación pero envolviendo todo en una historia de ficción de buenos y malos en el que la gente se ve implicada a través de retos, desafíos, pistas ofrecidas a través de códigos QR... Quizá por eso el autor bautiza el experimento como social benefit storytelling, un nuevo género dentro de esta lógica digital participativa. La primera acción filantrópica empezó en Londres en 2010, tal como se recoge en el vídeo London Experience, tras cuya movilización de ciudadanos en pos de diversos retos se logró una suma de dinero para financiar bibliotecas en África.

Las narrativas participativas son, por tanto, un instrumento idóneo para crear comunidad, y eso también afecta a esos universos transmedia que engloban parte de las experiencias relatadas. Si queremos contar con una comunidad implicada que pueda proyectarse hacia un fandom específico debemos contar con ello, como se ha demostrado ampliamente en la televisión. ¿Es posible una fórmula exitosa para una fórmula transmedia que se sustente en sí misma? Eso es lo que se plantea Daniela M. Sasaki en su tesis (2012), pregunta que nosotros asumimos. En cualquier caso, la interacción entre narrativa y tecnología es incuestionable: «Este escenario nos obliga a replantear teorías y, sobre todo, a preguntarnos si debemos dejar de hablar tanto de contenido y comenzar a pensar en términos de relato. En cierto sentido ampliar la búsqueda de nuevos maridajes entre información, narrativas e interfaces para establecer historias que se adapten mejor a las audiencias actuales» (Liuzzi, 2014: 74).

\section{Diseñando comunidades de fans}

En Convergence Culture (2008) Jenkins plantea que los fans son la vanguardia de la audiencia. Para cualquier producto de la cultura digital, y un transmedia en particular, generar una comunidad es todo un logro, pero todavía es más valioso llegar a un fandom — fan + kingdom - , que nuestro universo tenga su propio «reino de fans». Para entender este fenómeno de la actual cultura digital participativa es necesario recurrir al concepto ya reseñado de engagement o implicación. Busse y Gray (2011) consideran al fan como un consumidor superior a la media en cuanto a ese compromiso, que también se proyecta luego en otros comportamientos, como capacidad de recomendación de una marca, etcétera. Esos autores clasifican los usuarios compaginando dos coordenadas: psicológicamente involucrados y socialmente implicados. 
1. Los espectadores ampliamente involucrados y como audiencia implicada son fans de estilo de vida.

2. Los espectadores involucrados pero no socialmente implicados están comprometidos con un producto cultural pero aislados socialmente y, por tanto, con poca influencia.

3. Los espectadores muy implicados pero psicológicamente no involucrados son los que son influenciados por sus pares.

4. Los espectadores que ni están involucrados ni implicados son transeúntes, la audiencia menos valiosa.

Solamente una minoría de la audiencia adquirirá el compromiso total de un fan (Evans 2011), limitándose la audiencia mayoritaria a leer y experimentar un texto mediático, mientras otros van adquiriendo esos niveles de implicación que apuntan al interactor colaborando, moderando discusiones y liderando desarrollos. Está demostrado que en un juego de realidad aumentada, por ejemplo, el 75\% escogerá vivir pasivamente la experiencia, un $20 \%$ se enganchará en la dinámica lúdica y un $5 \%$ contribuirá a los contenidos. El transmedia storytelling tiene la dificultad de que genera una mastermind narrative que dificulta la experiencia global de todo el universo. El caso de Matrix —estudiado por Jenkins, Dena o Leiter- pone de manifiesto que las audiencias medias no estaban preparadas para explorar toda la complejidad del universo y sus secuelas. En Plot 28 ha ocurrido algo parecido.

Dirigirse prioritariamente a la audiencia fan genera fracaso, como ocurrió con la película Attack of the Clones; sin embargo, otros casos en los que se pensó en una recepción más amplia tuvieron más éxito en la medida que asumieron retos transmediales, como es el caso de las series televisivas Lost y Dr. Who. Los productos transmedia con vocación innovadora tienen que tratar con la exclusión de las audiencias mainstream a través del principio de diseño de producto llamado tiering, es decir, dirigirse a diferentes audiencias con diferentes contenidos en diferentes medios y entornos (Dena, 2009). Esto ha sido bastante aplicado en las campañas de literatura juvenil, pero también en los juegos de realidad aumentada. Este método no implica transmedialidad, aunque puede ser un principio muy operativo en las estrategias transmediáticas. Nosotros lo hemos planteado en el universo Plot 28, en cuyo despliegue se pueden encontrar junto a los «contenidos base» más complejos — textos literarios y falsos documentales- otros contenidos más lúdicos y de corto recorrido, sobre todo en las pestañas interrogantes, pruebas y plotys. No por casualidad estos llaman más a la interactividad y abren la posibilidad de una prosumición, vías abiertas hacia la creación de un fandom de plotys ${ }^{11}$.

Un productor de contenidos contemporáneo, en su aproximación a la innovación y distribución de productos mediáticos, debería tener un buen conocimiento de las relaciones entre el buen conocimiento de las convenciones estéticas y los comportamientos de la audiencia. Hay que considerar muy particularmente las audiencias comprometidas, pero también las que buscan diversos niveles de compromiso. El desafío de un producto transmedial centrado es reconciliar la lógica del negocio con

\footnotetext{
${ }^{11}$ Estas medidas se recogen en el apartado «Difusión en la placenta de la cultura digital participativa» (Hernández, 2015: 228-231).
} 
la de la audiencia y la estética en un abanico de ofertas. La vocación de un universo transmedia es contar con una comunidad fan cohesionada y continuada. No es un reto fácil, sobre todo porque finalmente quien tiene la última palabra son los usuarios. Es nuestra responsabilidad como diseñadores de producción poner las plataformas, canales y medidas adecuados, pero el engagement de la audiencia está sometido a factores que no podemos controlar del todo. No debemos olvidar que, una vez disparada la dinámica fan, es casi imposible controlarla desde las instancias productoras, siendo esa comunidad la que lleva las riendas atendiendo a una lógica de una inteligencia emocional colectiva y en red. Como mucho, desde allí podemos aspirar a alimentar esa tendencia, canalizarla parcialmente y aprovechar su corriente positiva.

Uno de los aspectos más dinamizadores de la cultura fan asociada a un producto cultural es cuando se activan las mecánicas prosumidoras y los seguidores se aplican a la creación de productos marcados por su adscripción a la propuesta. Estamos hablando de la fanfiction. La primera plataforma de este corte, precisamente denominada Fanfiction, fue creada en 1998 por el programador Xing Li y desde entonces estas no han hecho sino reproducirse y hacerse más complejas. Star Wars es un buen ejemplo de aceptación de las fanfictions por parte de la productora, llegando a crear los Star Wars Fan Film Awards en 2002 y la Starwars.com con espacio para que los seguidores comprometidos subieran sus obras con la única condición de que cedieran la propiedad intelectual a Lucasfilm. Por el contrario, Harry Potter gestionó bastante mal actividad de los fans desencadenando la Potter War; la productora llegó a demandar a los niños más implicados por hacer vídeos propios, crear webs o wikis para compartir sus visiones sobre ese universo mágico; usuarios, prensa y hasta la Iglesia se posicionaron contra la Warner Bros., que tuvo que rectificar.

¿Cómo podemos activar las fanfictions desde el diseño de producción? Ya hemos dicho que el protagonismo de estos procesos está en los usuarios convertidos en fans, pero no es menos cierto que un buen diseño de mapas de contenidos y plataformas contribuye a ese movimiento. Los seguidores implicados no surgen por generación espontánea, sino que son consecuencia de una siembra de temáticas, personajes y tramas que enganchan — como en las narrativas tradicionales-, pero que en el caso transmedia hay que añadir unos esquemas de presentación inteligentemente dosificados y escalonados, una presentación y diseño atractivos y los oportunos señuelos sembrados. En definitiva, que el mundo ficcional se haga suficientemente atractivo, genere empatías y provoque esa generación de contenidos relacionados que suponen las fanfictions. Además de estrategias mercadotécnicas o de community managements, que trataremos más adelante, hay otras fundamentalmente narrativas que contribuyen a crear ese territorio fandom tan deseado. El universo narrativo no tiene que percibirse como algo complejo, hermético, refractario, sino que tiene que aparecer como poroso, atractivo y abierto. Como estrategia complementaria se promoverán los interrogantes activos, interpelaciones de los personajes, un diseño impactante y manipulable. Sin olvidarnos de los ganchos, preguntas y llamadas a la continuidad y a la deconstrucción; en definitiva, esa apertura que requiere cualquier seguidor para tomar el testigo y referenciar desde su propia creatividad. Aquí la persuasión y el humor 
que desprenda el universo son dos valores fundamentales para suscitar esa corriente negociadora en el potencial fan.

¿Están los fenómenos de prosumición y fanfiction enfrentados dialécticamente a la interacción con plataformas y canales? Ciertamente, no estamos ante dos esferas enfrentadas, aunque tienen sus protocolos particulares en la medida que reflejan la tensión potencial entre productores y usuarios. Una buena disposición de nuestros mapas de contenidos, así como el despliegue clarificado de canales y plataformas desde el diseño de producción, va a facilitar la emergencia de un fandom asociado a nuestra propuesta transmediática, así como el fomento de la prosumición. A partir de ahora vamos a concretar de qué manera se puede aprovechar esa potencial convergencia, basándonos sobre todo en nuestra experiencia en el diseño de producción y posterior gestión del universo Plot 28 (2013). En primera instancia deberíamos considerar que cualquier diseño de mapas de contenidos, canales y plataformas de un universo mediático debe hacerse pensando en la audiencia, así como la trazabilidad de las intermediaciones y demediaciones. No solo porque se trate de una producción costosa —en inversión económica, medios, tiempo y trabajo creativo-, sino porque está integrada en la dinámica de una cultura digital que es inexorablemente participativa, en red y marcada por la inteligencia colaborativa. Pero en este diseño, productores y creadores de contenidos han de pensar igualmente en esas figuras emergentes dentro de la audiencia que son prosumidores y fans y sus canales de conexión más habituales. Y eso nos conduce de manera preeminente a las plataformas más accesibles y universales, y sin duda la Red ostenta el liderazgo en esa capacidad de albergar, distribuir y difundir los productos digitales. En consecuencia, otorgaremos a Internet, a través de una página o portal operativos, toda la prioridad, pues sin duda esa será la plataforma de contacto, conexión e interlocución con nuestra audiencia. En el caso de Plot 28, si bien el producto se comercializa a través de una aplicación en Apple Store, el sitio www.plot28.com es el principal muestrario donde se ofrecen todos los contenidos. Muchos de ellos están íntegramente a libre disposición de los usuarios en esa web, según una lógica escalable que va dosificando la información; los contenidos premium, en este caso los dos documentales y los dos textos literarios (Novela navegable y Bitácora a la deriva), se reservan para la aplicación de pago, bien a través de un app íntegro, bien a través de ibooks independientes.

Sin duda las plataformas de pago son una limitación con vistas a que prenda la mecha de los fans o de los prosumidores, por eso se puede optar por un modelo abierto —el más recomendable para estos fines- o por otro mixto como el de Plot 28. Aquí nos encontramos con el problema de la monetarización que normalmente ha de hacerse a través de una de esas plataformas por la vía de micropagos por contenidos. Los modelos de negocio que funcionan en el ámbito digital, y también en los del fandom y prosumición, son aquellos que alcanzan sus beneficios de manera indirecta. Los seguidores potencialmente implicados son en general refractarios a engancharse a aquello que les cuesta dinero, a no ser que la oferta sea muy clara. También es importante plantearse la relación de fans y prosumidores con los distintos canales que se les ofrecen para acceder a los contenidos. Para ambos destinatarios conviene que esos canales ofrezcan una llamada a ampliar los contenidos allí presentes, bien porque sean fácilmente realizables con programas conocidos, bien porque ponemos a 
libre disposición interfaces de participación abiertos y de fácil manejo para los usuarios. En cualquier caso, las reglas de juego deben ser muy transparentes a la vez que se busca esa colaboración o potencial difusión con persuasión y humor.

\section{Cultura fan, CGU y redes sociales}

La cultura fan con sus fanfictions y las aportaciones creativas de los prosumidores relacionados con un determinado producto cultural se expresan y canalizan, como hemos visto, principalmente en la web 2.0. Pero cada vez más las redes sociales son los nervios por donde se viralizan todos esos contenidos. En el diseño de producción de un universo transmediático se tiene que tener muy en cuenta esta interacción. No basta con un buen plan de community management tradicional, hay que contar con otro específico para incentivar la parte más activa de la comunidad que está constituida por los fans, prosumidores y canalizadores. ¿Cómo se produce esa interacción? Ya hemos afirmado anteriormente que aquí hay una parte no controlable, que está en manos del azar, vinculada al grado de empatía y conexión que suscite el universo hasta el punto de promover ese fandom y los productos derivados. Las redes sociales de nuestro universo deben seguir las pautas que recomiendan los especialistas y que avala la experiencia creativa. Y en este sentido esta nada fácil relación entre los dos ámbitos que hemos definido debe ser presidida por un principio de discreción. Los usuarios no soportan en general en las redes sociales los tonos invasivos, dirigistas, impositivos, coercitivos, clausurados. La presencia de una página Facebook de un universo transmedia, por ejemplo, debe ser discreta y centrada en los márgenes diegéticos de ese universo. Resulta extraño cuando en ese Facebook de una propuesta de ficción se hacen intromisiones o se cuelan opiniones sobre temas de actualidad, con toda la polémica sociopolítica que eso conlleva. A no ser que lancemos un producto deliberadamente activista, es mejor no pisar terrenos pantanosos limitándonos a los márgenes fabulados que nos hemos marcado.

La página de Facebook de nuestro universo (los perfiles no son operativos para este fin) tiene que constituirse en una plataforma dinamizadora, sembradora de retos, propuestas atractivas... Y en este sentido las estrategias de gamificación resultan efectivas. Lo mismo vale para Twitter, si bien asumiendo su carácter más dinámico y las prestaciones que ofrece como vehículo de eslóganes, frases, imágenes o enlaces. Y algo parecido podríamos decir de otras redes sociales teniendo en cuenta sus especificidades particulares y los objetos que vehiculan. El mismo principio de discreción invasiva vale para este microblog. Esta estrategia de proponer más que de informar, de sugerir más que de afirmar, de suscitar, atraer, seducir, facilitar es la que puede conectar con el potencial fan o prosumidor. Y en este sentido los ejemplos o los productos que hayan elaborado nuestros aliados más cercanos son señuelos que también operan en este sentido.

Otros aliados importantes de cara a la virtual interlocución con potenciales fans y prosumidores son los propios personajes de nuestro universo. Los protagonistas podrán cobrar vida a través de sus propios perfiles en las principales redes sociales, si bien esto es supone una gran inversión en dedicación del equipo o asumir la adquisición de programas que aportan plataformas de socialización, 
como Conductrr. En este sentido no hay que olvidar que nuestros potenciales seguidores dependen del enganche que les susciten principalmente los personajes; así ocurrió en la primera plasmación de una cultura de masas - Hollywood - con el banderín de enganche de los actores, y así acaece en nuestro cosmos digital aunque contando con este nuevo medio de difusión que son las redes sociales. De su utilización discreta, atractiva, incentivadora dependerá el éxito de nuestra propuesta de cara a la comunidad fandom y los productos generados por usuarios que derive.

\section{Conclusión: hacia una experiencia inmersiva}

Concluiremos enfatizando dos variables fundamentales que han sido refrendadas tras la argumentación precedente. En primer lugar, la importancia creciente que en el ámbito transmedia está adquiriendo un diseño de producción consciente; en segundo lugar, la importancia incuestionable de una audiencia participativa con vocación prosumidora para consolidar cualquier transmedia storyworld. Esos receptores participativos tienen que ser buscados desde el propio diseño de producción, en el diseño de mapas de contenidos y de plataformas, así como a la hora de configurar el universo transmediado como una experiencia inmersiva. Ambos aspectos han sido oportunamente resaltados por Sánchez-Mesa y Baatens (2017: 10): «Es significativo, cuando se lee, cuatro años después, la nueva definición ofrecida por Pratten en la segunda edición de su libro, el desplazamiento hacia la centralidad de la "experiencia" de los usuarios, donde el Transmedia Storytelling se entiende ya como una "filosofía del diseño de producción", cuyo énfasis no descansa ya tanto en el componente "multiplataforma" como en facilitar "a synergy between the content and a focus on emotional, participatory experience for the audience" (Pratten, 2015: 3)».

No es casual que precisamente Robert Pratten, otro creador transmedia con capacidad de reflexionar sobre sus obras, haya resaltado también estos temas otorgándole un papel relevante al transmedia production design.

\section{Bibliografía}

Abellán HernándeZ, M. - De Miguel ZAmorA, M. (2016): «Narrativa transmedia: resignificando el consumo mediático. Presentación», Icono14, 14, pp. 1-7.

ANDREJEVIC, M. (2007): iSpy: Surveillance and Power in the Interactive Era. Lawrence, University Press of Kansas.

ARDÉvol, E. - RoIG, A. - GómEZ, E. - SAN CORNELIO, G. (2010): «Prácticas creativas y participación en los nuevos media», Cuadernos de CAC, 34, en http://www.cac.cat/pfw_files/cma/recerca/ quaderns_cac/Q34_Ardevol_et_al._ES.pdf (última consulta, 7-10-2010).

BENNERS-LEE, T. (1997): «Realising the full potential of the web», en http://www.w3.org/1998/02/ Potential.html (última consulta, 5-7-2013).

BRuns, A. (2007): Produsage: A Working Definition, en http://produsage.org/node/9 (última consulta, 5-1-2011). 
Buskqvist, U. (2009): «Interaktivitet (Interactivity)», en P. BERGLEZ y U. Olausson, eds., Mediesamhället (Media society). Lund, Centrala Begrepp Lund, Studentlitteratur.

Busse, K. - Gray, J. (2011): «Fan Cultures and Fan Communities», en V. Nightingale, ed., The Handbook of Media Audiences. Chichester, Wiley-Blackwell, pp. 427-442.

CARPENTIER, N. (2011): Media and Participation: A Site of Ideological-Democratic Struggle. Bristol, Intellect, en http://www.dawsonera.com.proxy.mah.se/depp/reader/protected/external/EBook View/S9781841505244/S6 (última consulta, 6-6-2012).

Costa SÁnCHEZ, C. (2013): «Narrativas Transmedia Nativas: Ventajas, elementos de la planificación de un proyecto audiovisual transmedia y estudio de caso», Historia y Comunicación Social, 18, pp. 561-574.

Chan-Olmsted, S. (2005): «Response to Diversification Strategy of Global Media Conglomerates: a comment», Journal of Media Economics, 18/2, pp. 105-107.

DAVIS, C. H. (2013). «Audience Value and Transmedia Products», en T. STORSUL y A. H. KRUMSVICK, eds., Media Innovations. Göteborg, Nordicom.

Deltell Escolar, L. (2014): «Audiencia social versus audiencia creativa: caso de estudio Twitter», Estudios sobre el Mensaje Periodístico, 20/1, pp. 33- 47.

DenA, C. (2009): Transmedia Practice: Theorising the Practice of Expressing a Fictional World across Distinct Media and Environments. Sidney, University of Sydney, en http://cirettransdisciplinarity.org/biblio/biblio_pdf/Christy_DeanTransm.pdf (última consulta, 21-7-2017).

Deuze, M. (2007): «Convergence Culture in the Creative Industries», International Journal of Cultural Studies, 10, pp. 243-263.

EDWARDS, L. H. (2012): «Transmedia Storytelling, Corporate Synergy, and Audience Expression», Global Media Journal, 12/20, pp. 1-12.

Evans, E. (2011): Transmedia Television. Audiences, New Media and Daily Life. New York, Routledge.

Ford, S. - De KosniK, A. - HARRINGTOn, C. L. (2011): The Survival of Soap Opera: Transformations for a New Media Era. Jackson, University Press of Mississippi.

Gallego Aguilar, A. F. (2011): Transmediáticas. Guía de referencia para las industrias creativas de países emergentes en el contexto de la cibercultura. Manizales, Universidad de Caldas, en http://www.afoxcp.com/dw/Diseno_narrativas_transmediaticas_Gallego_2011.pdf (última consulta, 21-7-2017).

Gauntlett, D. (2011): Making Is Connecting: The Social Meaning of Creativity, from DIY and Knitting to YouTube and Web 2.0. Cambridge, Polity.

Green, J. - Jenkins, H. (2009): «The Moral Economy of Web 2.0. Audience Research and convergence culture», en J. Holt y A. Perren, eds., Media Industries. History, Theory, and Method. Chichester, Wiley-Blackwell.

HERNÁNDEZ RUIZ, J. (2015): «Plot 28, un pionero universo transmedia que radiografía el poder alienante del capitalismo de escaparate en España», Espéculo, 54, pp. 221-223. 
(2017): «Storytelling», en C. OBANDO y J. HERnÁNDEZ RuIZ, eds., La Metafísica de Internet. Nuevas formas de relato en la cultura digital participativa. Zaragoza, USJ Ediciones (en prensa).

HAYES, G. (2007): The myth of web 2.0 non-participation, en http:/www.flickr.com/photos/ garyhayes/3251571301/in/photostream (última consulta, 30-7-2010).

Howe, J. (2006): «The Rise of Crowdsourcing», Wired Magazine, en http://www.wired.com/wired/ archive/14.06/crowds_pr.html (última consulta, 25-7-2015).

Jenkins, H. (2008): Convergence Culture. La cultura de la convergencia de los medios de comunicación. Trad. Pablo Hermida Lazcano. Barcelona, Paidós.

- (2009): Fans, blogueros y videojuegos. La cultura de la colaboración. Barcelona, Paidós.

Jenkins, H. - Ford, S. - Green, J. (2013): Spreadable Media. Creating Value and Culture in a Networked Culture. New York, NYU Press.

Jenkins, H. - ITO, M. - BoyD, D. (2016): Participatory Culture in a Networked Era. A Conversation on Youth, Learning, Commerce, and Politics. Cambridge, Polity Press.

KozINETS, R. V. (1999): «E-tribalized marketing?: The strategic implications of virtual communities of consumption», European Management Journal, 17/3, pp. 252-264; en http://www. sciencedirect.com/science/article/pii/S0263237399000043 (última consulta, 21-7-2017).

KRING, T. (2010): Conspiracy for Good, en http://www.conspiracyforgood.com/wwd.php (última consulta, 17-11-2016).

LASTRA, A. (2016): «El poder del prosumidor, identificación de sus necesidades y repercusión en la producción audiovisual transmedia», Icono14, 14, pp. 71-94.

LÉVY, P. (2004): Inteligencia colectiva por una antropología del ciberespacio, en http://inteligenciacolectiva.bvsalud.org/?lang=es (última consulta, 10-6-2010).

LIUZZI, A. (2014): «Transmedia "Historytelling”. De Documentales Interactivos y Géneros Híbridos», en F. IrIGARAY y A. LoBATO, eds. Hacia la comunicación transmedia $\left(6^{\circ}\right.$ Foro Internacional de Periodismo Digital. $1^{\circ}$ Encuentro de Narrativas Transmedia). Rosario, UNR.

MCCRACKEN, G. (2005): “Consumers” or "multipliers” A new language for marketing?», en http://cultureby.com/2005/11/consumers_or_mu.html (última consulta, 20-10-2010).

NEALE, L. (2010): «Loyalty and the Ritualistic Consumption of Entertainment», Continuum: Journal of Media and Cultural Studies 24/6, pp. 905-919.

Pratten, R. (2015): Getting Started in Transmedia Storytelling. A practical Guide for Beginners. $2^{\mathrm{a}}$ edición ( $1^{\mathrm{a}}$ ed. online en http://www.tstoryteller.com/getting-started-in-transmedia-storytelling; última consulta, 5-7-2017).

Rose, F. (2011): The Art of Immersion. New York, W. W. Norton.

SÁnchez-Mesa, D. - AARSETh, E. - PrATten, R. - SCOlARI, C. (2016): «Transmedia (storytelling?). A polyphonic critical review», Artnodes, 18, pp. 8-19.

SÁNCHEZ-MESA, D. - BAETENS, J. (2017): «La literatura en expansión. Intermedialidad y transmedialidad en el cruce entre la literatura comparada, los estudios culturales y los new media studies», 
Tropelías. Revista de Teoría de la Literatura y Literatura Comparada, 27, pp. 6-27; en https://papiro.unizar.es/ojs/index.php/tropelias/article/view/1536 (última consulta, 15-7-2017).

SASAKI, D. M. (2012): Transmedia Storytelling and Lost Paht to Succes. Jyväskylä, University of Jyväskylä, en https://jyx.jyu.fi/dspace/bitstream/handle/123456789/38244/URN:NBN:fi:jyu201207192109.pdf?sequence=1 (última consulta, 21-7-2017).

SCOLARI, C. (2013): Narrativas transmedia. Cuando todos los medios cuentan. Barcelona, Deusto.

STEIN, L. E. (2017): «Fandom and the Transtext», en B. W. L. DeRhy KuRTZ y M. BourdAA, eds., The Rise of Transtexts: Challenges and Opportunities. Nueva York / Londres, Routledge, pp. 70-89.

TAPSCOTT, D. - Williams, A. (2006): Wikinomics: How Mass Collaboration Changes Everything. New York, Portfolio.

TOFFLER, A. (1980): The Third Wave. New York, Bantam.

THRIFT, N. (2006): «Re-inventing Invention: New Tendencies in Capitalist Commodification», Economy and Society, 35/2, pp. 279-306.

VAn DiIJCK, J. (2013): The Culture of Connectivity: A Critical History of Social Media. New York, Oxford University Press.

Wenger, E., White, N., Smith, J., Y Rowe, K. (2005): Technology for communities. CEFRIO (Research Institute in Canada), en: http://technologyforcommunities.com/CEFRIO_Book Chapter_v_5.2.pdf (última consulta, 29-4-2009). 